\title{
Performance study of exotic variety of potato (Solanum tuberosum L.) for processing industry under the agro- climatic condition of Lahore-Pakistan
}

\author{
Sana Khalid ${ }^{1,2^{*}}$, Shabnum Shaheen ${ }^{1}$, Ammara Ishfaq ${ }^{3}$ and Riffat \\ Siddique ${ }^{1}$ \\ 1. Lahore College for Women University, Jail Road, Lahore-Pakistan \\ 2. Institute of Agricultural Sciences, University of the Punjab, Lahore-Pakistan \\ 3. Hafiz Hayat Campus, Jalalpur Jattan road, University of the Gujrat-Pakistan \\ *Corresponding author's email:sanakhalidpu@gmail.com
}

Citation

Sana Khalid, Shabnum Shaheen, Ammara Ishfaq and Riffat Siddique. Performance study of exotic variety of potato (Solanum tuberosum L.) for processing industry under the agro-climatic condition of Lahore-Pakistan. Pure and Applied Biology. Vol. 8, Issue 4, pp2262-2268. http://dx.doi.org/10.19045/bspab.2019.80172

Received: 25/05/2019 Revised: 14/07/2019

Accepted: 16/07/2019

Online First: 23/07/2019

\section{Abstract}

Potato (Solanum tuberosum L.) crop is popular among the farming community for its high production per unit area and consequently high returns, therefore three crops of potato autumn, spring from plains and summer from high hills, are being grown in Pakistan. Its utilization as fast food and use for processing has further increased its importance among farmers, consumers and processors. With the aim in mind to enhance the farmer's earnings by introducing new varieties of potato for processing and fresh market, current trial was performed to check the adaptability of exotic potato variety 'Melanto' (Cross: Impala $\times$ POS 97-1) in field trials, farms situated at Bedian Road, Lahore Cantt. Pakistan. This exotic varsity is better adapted specifically to summer, fall and spring cultivation districts of the Punjab, Pakistan. Big oval tubers produced with $17.5 \%$ dry matter content was ranked under cooking type $A$, i.e., no discoloration after cooking. 'Melanto' showed resistance to potato cyst nematodes Ro 1 and Ro 4 having relatively longer dormancy period than the control verity 'Desiree'. The highest yield $30.46 \mathrm{t} / \mathrm{ha}$ (ton/hectare) was recorded for 'Melanto' followed by 'Desiree' $22.07 \mathrm{t} / \mathrm{ha}$. But both varieties were found susceptible under high infection of late blight. Therefore, it can be concluded that the development and accessibility of new varieties of potato which are suitable for the processing is quite critical for sustaining the rise in processing industries of Pakistan. Moreover, the potato verities with more dry matter and less reducing sugars are required by potato processing industry to ensure high quality processed products. Enhancement in the production of potato is just due to the application of modern technologies and utilization of new seed varieties. White potatoes and the red potatoes are the major contributors in potato production by volume in Pakistan.

Keywords: Adaptability test; Emergence percentage; Melanto; Solanum tuberosum L.

\section{Introduction}

Potato (Solanum tuberosum L.), king of vegetables belonging family Solanaceae being a multipurpose food crop ranked third in the list as world's most popular food hence extensively grown over the world including Pakistan [1, 2]. It is cultivated on an area of 149,00 hectares, yielding 4,104,400 tones 
and national average yield is 22.89 tones/ha with $14 \mathrm{~kg}$ per capita annual consumption and current population of $\sim 170$ million $[3,4]$. Along with abiotic stress, fungal and viral diseases are also reported to cause decrease in yield and responsible for economic losses. Among these a serious threat to potato is late blight caused by Phytophthora infestance and its control is still a major bottle neck whereas, three billion US dollar/annum loss in yield has been recorded due to late blight in the world [5-7]. Despite many folds increase in potato yield, still yield/acre is quite less in Pakistan than other countries [8]. On the other hand developed countries are more efficient in processing of potatoes but now in developing countries this industry also got attraction due to an increased trend in urbanization, fast foods and easy-to-prepare, taking higher/capita income, preference for ready cooked food due to rise in number of working women as well as enhanced tourist trade $[9,10]$. Beside potato use for backing, cooking, chips and fries processing of potato offers both preservation and value addition but it depends on high quality traits of potato. Hence, main constraint for boosting of potato processing industry is non-availability of quality raw material [11]. Nevertheless, in Pakistan this industry is also booming day by day which is directly linked with the constant supply of fresh and suitable potato varieties during whole year. However, after December-May potato industry depends on stored potatoes of clod stores which is very costly or depends on other growing areas with limited supply. Therefore in Pakistan, for maintaining the growth of potato processing industry as well as development and accessibility of suitable varieties is prerequisite. Furthermore the traits like more dry matter and less reducing sugars are essential for selection of varieties which is positively correlated with recovery of high quality processed product. If any appropriate variety, with showed acceptable chipping ability under various seasons, can be established which lead to provision of fresh potatoes for processing $[12,13]$. Whereas, a significant increase has been reported in Pakistan for potato consumption but processing characteristics and yield of few recently introduced (exotic) varieties mostly remains unidentified. These different varieties vary in their uses and characteristics. However, knowing about the favored requirements for each use and selection of varieties those have the particular traits to meet up these requirements, it very important. This will lead to increase in growers the ability to convene the challenge of rapidly changing production and market circumstances, potentially improving and maintaining their economic prosperity. The main purpose for the development of new verities was to consider user liking and local situation, when commenced into a country. Many hundred varieties of this well-liked vegetable are grown today, all around the world, which vary in texture, shape, flavor and color, considering the suitability for end use [14]. All over the world many varieties of potato have been developed and introduced and released to farmers, over the years. These varieties exhibited considerable tuber characteristics; however, processing quality of such varieties for French-fries and chips is generally unidentified [15]. Basically, two very important factors are accountable for establishing potato processing sector. First, the ease of local varieties of potato for processing and the second, diverse agro-ecological conditions required for the cultivation of these varieties aimed for enough and continuous delivery of raw material for the processing industry [12, 16, 17]. Numerous indigenous and exotic genotypes are accessible in Pakistan but there is an urgent need for the selection and evaluation of potato genotypes, which are exhibiting better yield, processing and storage traits to meet the requirements and 
challenges of changing market faced by growers. 'Melanto' (Cross: Impala $\times$ POS 971 ) is approved for import in Pakistan and is registered with FSC \& RD Islamabad so that seed may multiply here in Pakistan to provide best certified seed to farmers to enhance the potato production and earn valuable foreign exchange for country. Therefore, the current adaptability trial was conducted to determine the germination potential and yield of the exotic variety 'Melanto' in different areas of Pakistan including hilly areas [18].

\section{Materials and methods}

\section{Experimental design}

Current paper pertains to local and exotic varieties of potato in field area situated at Bedian Road, Lahore and the treatments were given on Randomized Complete Block Design (RCBD) covering three (3) blocks in triplicate. Each block consisted of six (6) plots with a measurement of $5 \mathrm{~m}$ long and 3 $\mathrm{m}$ wide. For sowing, plant to plant (9 inches), and row to row (75 centimeter) distances were maintained. Standard plant protection and agronomic practices were followed to raise the crop successfully. The experiment was conducted for two consecutive seasons, namely, September 2012 to January 2013 and February 2013-May 2013. The local (Desiree) was used as a check variety and exotic (Melanto) varieties of potato were procured from the Hunza seed crops, PVT Ltd. Pakistan. Crop was monitored regularly throughout the crop season.

\section{Dehaulming of crop}

Dehaulming, at crop maturity was done and after 15 days of dehaulming tubers were harvested to firm up the tuber skin. Emergence percentage by counting the number of plants emerged after 45 days from the day of planting was noted from a specified $15 \mathrm{~m}^{2}$ (meter square) area of every treatment. Marketable and yield $\mathrm{t} / \mathrm{ha} \mathrm{s}$ were studied after recording the data about stem $/ \mathrm{m}^{2}$ and tubers $/ \mathrm{m}^{2}$. The level of the incidence of late blight disease of economic importance under natural field conditions was also determined.

\section{Data collection}

Parameters regarding up-ground morphology like, plant, foliage structure, stem, anthocyanin color, color of leaf, silhouette, flower frequency, anthocyanin coloration: inner side of a flower was recorded. Tubers and sprouts characters were also recorded. At the time of harvesting, observations were noted. Tubers from $15 \mathrm{~m}^{2}$ area were weighed and counted. All tubers ( $>35 \mathrm{~mm}$ in diameter) considered as the marketable, obtained from $15 \mathrm{~m}^{2}$ area were weighed. The tuber sample was scored for shape i.e., 1 (Round); 2 (Round to short oval); 3 (Short oval); 4 (Short oval to oval); 5 (Oval); 6 (Oval to long oval); 7 (Long oval); 8 (Long oval to very long oval); 9 (Very long oval) according to the following key (Wooster and Farooq, 1995). Color of tuber skin i.e., red or white $\{1$ (Round); 2 (Round to short oval); 3 (Short oval); 4 (Short oval to oval); 5 (Oval); 6 (Oval to long oval); 7 (Long oval); 8 (Long oval to very long oval); 9 (Very long oval) $\}$ were observed visually instantly after harvesting. Ten (10) tubers from every treatment were slice into two halves for the assessment of the potato sample for the flesh color. From every treatment, ten tubers were sliced into two equal halves for the assessment of the potato sample for the color of the flesh $\{1$ (White); 2 (Cream); 3 (Yellow) \} was done as illustrated by [19]. Sample's evaluation, for the tuber eye depth $\{1$ (Very deep); 2 (Very deep to deep); 3 (Deep); 4 (Deep to medium); 5 (Medium); 6 (Medium to shallow); 7 (Shallow) 8 (Shallow to very shallow); 9 (Very shallow) was made as mentioned by [19].

\section{Results and discussion}

Current paper aims to estimate the emergence percentage, stem $/ \mathrm{m}^{2}$, tuber $/ \mathrm{m}^{2}$, marketable produce percentage, late blight infestation percentage and yield t/ha (Figure 1a,b,c) to local and exotic varieties of potato (Melanto 
\& Desiree) during field trial as these characters influence consumer choice. The exotic variety 'Melanto' gave high percentage of emergence $(96.2 \%)$ than 'Desiree' (91.8\%). Seed germination being first crucial and the greatest sensitive duration in the life span of plants which is influenced by seeds characteristics, developmental stages of seeds and genetic control under environmental conditions [2], [20], [21]. Therefore, the commercial producers of potato mostly need information to figure out time of emergence, population and uniformity of seedling. Consequently, the parameters such as seeds germination rate and percentage are specifically in relation to seed lot, temperature, water supply and seed treatments are very important. When seed is being sown in a germination medium such as soil then its germinability rely on environmental factors which indirectly influence the growth of seedlings and so the quality of crop with ultimate yield. Outcomes of the here in experiment exhibited that external factors were similar; hence difference in germination percentage might be noted due to internal genetic features [22]. Similarly, better performance was recorded for the variety 'Melanto' with long stolons as compared to the control verity 'Desiree'. The highest yield $30.46 \mathrm{t} / \mathrm{ha}$ was recorded for 'Melanto' followed by 'Desiree' $22.07 \mathrm{t} / \mathrm{ha}$. Whereas, the 'Melanto' produced more tuber $/ \mathrm{m}^{2}$ (50.76) as compared to 'Desiree' (38.21) with less stem $/ \mathrm{m}^{2}$ (16.97) which was 20.27 in 'Desiree'. It is very obvious from the results of the current study that 'Melanto' had more resistant to Late blight infestation (70.20\%) as compared to Desiree (81.20).

Data presented in (Table 1) depicts the various distinguished morphological characters of the 'Melanto' which shows that it is with medium to early maturity having average dormancy. Up ground characteristics of the potato are listed in (Table 1) which shows that plant height was medium to tall with upright stem having dark green leaves color. Moreover, flower frequency was high with intermediate too open silhouette. Tubers shape was oval to round with yellow color, medium rough skin. Flesh color was pale yellow bearing shallow eyes. Sprouts were medium ovoid having small terminal buds and many root tips. Intensity of anthocyanin was medium to strong whereas anthocyanin coloration of tip was weak [2]. It is evident from the results that more tubers $/ \mathrm{m}^{2}$ (50.76) were produced by the 'Melanto' as compared to 'Desiree' (38.21) because the number of tubers is correlated with stolons and stolons which tuberize which ultimately is controlled by both environmental and genetic attributes [23]. It has been reported that distinguish qualities of potato such as tuber shape, skin color, flesh color and eye depth) influence the consumer choice hence general appearance is most important feature. Moreover, many countries like India, Bangladesh and Pakistan prefer to use red potatoes whereas for chip making round to oblong tubers and for French-fries very long oval to oval shaped potatoes are also recommended. And to reduce the peeling losses in potato, medium shallow to shallow eyes are preferred $[12,16$, $18,24]$. It is well documented now that many loci determine skin color in potatoes and is genetically controlled factor $[20,25,26]$. Moreover, 'Melanto' is very strong to internal bruising but due to big size of tubers, careful harvesting to avoid mechanical damage is recommended. As this variety has an average dormancy hence it can be easily stored for shorter period but for longer storage, the use of well-equipped cold stores is necessary. Moreover, normal planting distance in the rows accompanying normal treatments for late blight is recommended [5, 6]. However, it is suggested to plant in soils of at least $10{ }^{\circ} \mathrm{C}$ (centigrade). Nevertheless, the 'Melanto' is resistant to Cyst Nematodes (Ro1 and Ro4) rather strong against common 
scab also shows high tolerance to late blight in the foliage and in the tubers is average [7].
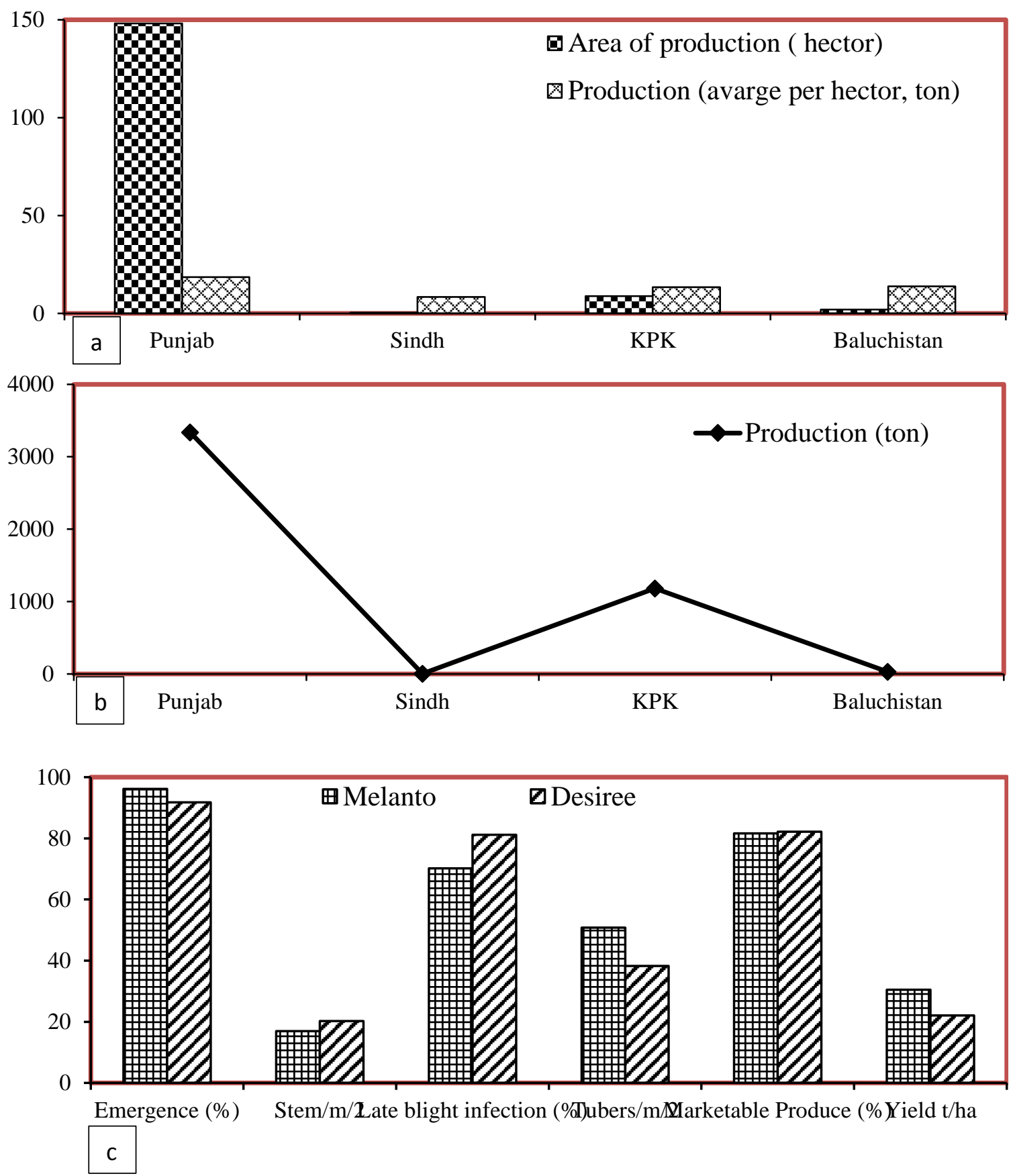

Figure 1. Potato production (a) area (hector) and the (b) production in ton and (c) performance of exotic potato variety 'Melanto' in comparison to local variety Desiree during 2013 
Table 1. Morphological characteristics of the exotic variety 'Melanto'

\begin{tabular}{|c|c|c|}
\hline S. No. & Character & Features \\
\hline 1 & Up-ground morphology & Medium to tall \\
\hline 2 & Plant & Intermediate type \\
\hline 3 & Foliage structure & Upright to semi upright \\
\hline 4 & Stem & Weak to large \\
\hline 5 & Anthocyanin color & Dark green \\
\hline 6 & Color of leaf & High \\
\hline 7 & Silhouette & Absent to very weak \\
\hline 8 & Flower frequency & Oval to round \\
\hline & Anthocyanin coloration: inner side of a flower & yellow \\
\hline 1 & Tubers & Medium rough \\
\hline 2 & Shape & Pale yellow \\
\hline 3 & Skin color & Shallow \\
\hline 4 & Skin & Medium ovoid \\
\hline 5 & Flesh color & Medium to strong \\
\hline & Eyes & Strong to medium \\
\hline 1 & Sprouts & Small terminal \\
\hline 2 & Sprout & Weak \\
\hline 3 & Intensity of Anthocyanin & Many \\
\hline 4 & Coloration pubescence base \\
\hline 5 & Buds & \\
\hline 6 & Anthocyanin coloration of tip & Root tips \\
\hline
\end{tabular}

\section{Conclusion}

Due to attack of late blight at bulk stage 'Melanto' was found susceptible like control variety Desiree. It can be concluded that this exotic variety has potential to get popularity among the potato growers in Pakistan as tubers of 'Melanto' were attractive in shape, color and having shallow eyes with smooth and shining skin.

\section{Authors' contributions}

Conceived and designed the experiments: $S$ Khalid, Performed the experiments: R Siddique, Analyzed the data: A Ishfaq, Contributed materials/ analysis/ tools: S Shaheen, Wrote the paper: S Khalid.

\section{Acknowledgment}

Potato seeds and field for planting were kindly supported by Hunza seed corporation (PVT) LTD Lahore, Pakistan which is highly acknowledged.

\section{References}

1. Salunkhe DK \& Kadam SS (1998). Handbook of vegetable science and technology: production, compostion, storage, and processing. CRC press.
2. Abbas G, Hafiz IA, Abbasi NA \& Hussain AZHAR (2012). Determination of processing and nutritional quality attributes of potato genotypes in Pakistan. Pak J Bot 44: 201-208.

3. GOP (2012). Agriculture Statistics of Pakistan, Ministry of food, Agriculture and Livestock, Govt. of Pakistan, Islamabad. pp 82.

4. FAOSTAT (2014). www.potatopro.com/world/potatostatistics

5. CIP (1997). Annual report. The International potato centre. Lima Peru, pp. 178.

6. Farooq K, Mahmood MM, Sher R \& Khan DI (2002). Evaluation of CIP potato germplasm for late blight resistance during summer season in Sharan, Kaghan Valley. Asian J Plant Sci 1(2): 195-196.

7. Singh B P, Kaushik SK, Singh PH \& Joseph TA (2003). Potato late blight and its management. Indian Farming 53: 19-23.

8. Malik NJ (1995). Potato in Pakistan. A Hand Book. Pak-Swiss Potato Development 
Project, Pakistan Agriculture Research Council, Islamabad, 99-160.

9. Marwaha RS, Pandey SK, Singh SV \& Kumar D (2007). Yield, chipping and nutritive qualities of spring grown potatoes in north-western plains. Potato $J 34(1-2)$ : 61-62.

10. Marwaha RS (1997). Processing of potatoes: Current status, need, future potential and suitability of Indian varieties: A critical appraisal. J food Sci Technol 34(6): 457471.

11. Singh BP \& Bhat MN (2005). Development, issues and strategies for the management of potato late blight. Potato J 32: (3-4).

12. Pandey SK, Singh SV, Kumar D, Kumar P \& Manivel P (2004). Sustaining potato chipping industry from western and central Uttar Pradesh: Adoption of suitable varieties. Potato J 31: (3-4).

13. Khan MA, Hafiz IA, Farooq K, Abbasi NA \& Razzaq A (2014). Evaluation of potato hybrids for yield components in humid subtropical climate during autumn season. JAPS 25(5): 1511-1517.

14. O'Connor CJ, Fisk KJ, Smith BG \& Melton LD (2001). Fat uptake in French fries as affected by different potato varieties and processing. J Food. Sci 66(6): 903-908.

15. Tawfik AA, Mansour SA, Ramadan HM \& Fayad AN (2002). Processing quality of selected potato varieties for chip and French fry industries in Egypt. African. Crop. Sci. J 10(4): 325-333.

16. Pandey SK, Singh SV, Kumar D, Manivel P, Marwaha RS, Kumar P \& Gupta VK (2008). Kufri Himsona: A chipping cultivar for hill regions of India. Potato J 35(1-2): 1-8.

17. Pandey SK, Singh SV, Kumar D, Manivel P, Marwaha RS, Kumar P \& Singh BP (2006). Kufri Chipsona-3: A high yielding potato variety for chipping with defect free tubers. Potato J 33: (1-2).

18. Pandey SK (2007). Approaches for breaching yield stagnation in potato. Potato J 34(1-2): 1-9.

19. Wooster P \& Farooq K (1995). National program of germplasm screening, general instructions for trial and guide to data collection. Pak Swiss Potato Development Project, PARC Isb, Pak 24.

20. Potato Genome Sequencing Consortium. (2011). Genome sequence and analysis of the tuber crop potato. Nature 475(7355): 189.

21. Wang R, Lihua L, Liu $\mathrm{H}$ \& Wang RG (1995). Present state of research on potato germplasm resources in China. Crop Genetic Res 3: 20-22.

22. Bugarcic Z, Vasiljeic Z, Šušic S \& Đokic A (1996, July). Phenotype values, variability and productive properties in Dutch potato varieties under different agro-ecological conditions. In I Balkan Symposium on Vegetables and Potatoes 462: 921-928.

23. Subarta M \& Upadhya MO (1997). Potato production in Western Bengal. Environ. Ecol 15: 646-9.

24. Kabira JN \& Lemaga B (2006). Potato Processing: Quality Evaluation procedures for research and food industries applications in East and Central Africa. Kenya Agric Res Institute, Nairobi, Kenya, pp 12.

25. Anwar J, Asi AR \& Tariq AH (1987). Screening of new exotic potato germplasm under Faisalabad conditions [Pakistan]. Pak $J$ Agric Res 8(3): 245-250.

26. Abbasi NA, Hafiz IA. \& Fazal BILAL (2004). Evaluation of exotic potato varieties in ecological conditions of Islamabad during autumn season. Inter J Agric Biol 3: 479482. 